\title{
PELATIHAN PEMANFAATAN E-LEARNING UNTUK MENINGKATKAN KOMPETENSI TIK BAGI GURU SMA DAN SMK JAKARTA
}

\author{
Anton Zulkarnain Sianipar ${ }^{1 *}$, Rachmawaty Haroen ${ }^{2}$ \\ ${ }^{1,2}$ STMIK Jayakarta \\ *Korespondensi: antonz.jayakarta@gmail.com
}

\begin{abstract}
ABSTRAK. Kebutuhan penguasaan teknologi yang bermanfaat dalam mendukung proses belajar mengajar sangat diperlukan oleh guru - guru SMA maupun SMK. Dalam kegiatan pengabdian masyarakat kali ini bertujuan untuk melatih pemanfaatan dan penguasan teknologi berbasis e-learning untuk meningkatkan kompetensi TIK bagi guru SMA dan SMK di wilayah Jakarta. Proses kegiatan dilaksanakan selama 1 hari, guru - guru diberikan pelatihan dalam bentuk pemaparan materi, diskusi dan Latihan menggunakan platform pembelajaran e-learning yang ada seperti google classroom, google form dan quizziz. Di akhir kegiatan diberikan kuis berbentuk google form untuk melihat tingkat penguasan pemahaman materi. Dari pelatihan ini guru - guru diharapkan dapat mampu mengaplikasikan ilmu yang diperoleh yaitu penggunaan pembelajaran e-learning di dalam kelas.
\end{abstract}

Kata kunci: Pelatihan; e-learning; Kompetensi TIK; Guru

ABSTRACT. The need for mastery of technology that is useful in supporting the teaching and learning process is very much needed by high school and vocational high school teachers. In this community service activity, it aims to train the use and mastery of e-learning-based technology to improve ICT competence for high school and vocational high school teachers in the Jakarta area. The activity process is carried out for 1 day, teachers are given training in the form of material exposure, discussions and exercises using existing e-learning learning platforms such as google classroom, google form and quizziz. At the end of the activity, a quiz in the form of a google form was given to see the level of mastery of understanding the material. From this training, teachers are expected to be able to apply the knowledge gained, namely the use of e-learning in the classroom.

Keywords: Training; e-learning; ICT competence; Teacher

\section{PENDAHULUAN}

Kemajuan teknologi terjadi sangat cepat akhir - akhir ini. Disamping dampak dari revolusi industry 4.0 dan juga era globalisasi. Dengan kemajuan teknologi tersebut, pendidikan sedikit banyaknya merasakan dampak tersebut. Guru sebagai aktor di dalam kelas dituntut untuk dapat beradaptasi dalam memanfaatkan kemajuan teknoloi. Teknologi Informasi dan Komunikasi (TIK) merupakan perangkat teknologi yang dimanfaatkan dalam pengelolaan data, penyusunan, penyimpanan dan manipulasi data melalui berbagai cara untuk memproses dan menyampaikan informasi yang berkualitas [1]. Dari hasil wawancara dengan kepala sekolah dan guru - guru mitra sekolah SMA dan SMK beberapa guru 
mengalami kesulitan dalam menggunakan teknologi informasi khususnya di bidang pembelajaran yang menggunakan e-learning. Dari sini didapatkan permasalahan mitra dan Langkah selanjutnya adalah menyepakati kegiatan yang akan dilaksanakan yaitu pelatihan untuk guru - guru SMA dan SMK. Dalam sebuah penelitian yang di lakukan oleh [2] bahwasanya e-learning sangat efektif pembelajaran. Pembelajaran e-learning pastinya sangat mudah diterima oleh peserta didik. E-learning juga di anggap sebagai media pembelajaran yang interaktif [3]. Sebelum dilaksanakan kegiatan pelatihan akan disusun terlebih dahulu modul sehingga bisa dengan modul tersebut diharapkan para peserta didik dapat mempelajari Kembali materi pelatihan di tempat para guru mengajar [4].

\section{METODE}

Kegiatan pengabdian masyarakat dilaksanakan beberapa tahapan sebagai berikut :

1. Persiapan.

Pada tahapan ini di awali dengan diskusi dengan mitra dan menanyakan permasalahan apa yang dihadapi oleh mitra dan memberikan solusi kepada mitra untuk menyelesaikan permasalahan mereka serta menyepakati waktu yang tepat untuk kegiatan pelatihan dilaksanakan.

2. Pelaksanaan.

Pada tahapan ini kegiatan dilaksanakan di ruang Laboratorium Komputer STMIK jayakarta. Karena di ruang Lab. Komputer jayakarta tersedia fasilitas yang cukup untuk para guru dalam mengikuti pelatihan. Kegiatan dilaksanakan dari pukul 09:00 - 12:00 Wib. Kegiatan dilaksanakan pemaparan materi oleh narasumber dan juga diskusi dengan para peserta, serta diberikan waktu bagi para peserta untuk melakukan praktik dan uji coba pemanfaatan e-learning (google classroom), mulai dari pembuatan akun, sampai pembuatan kelas dan juga pembuatan soal menggunakan google form.

Tabel 1 Jadwal Pelaksanaan Kegiatan Pengabdian Kepada masyarakat

\begin{tabular}{|c|c|c|}
\hline Waktu & Kegiatan & PIC \\
\hline $08: 00-08: 30$ & Persiapan & Panitia \\
\hline $08: 30-09: 00$ & Registrasi & Panitia \\
\hline $09: 00-09: 40$ & Pembukaan & MC \\
\hline $09: 40-09: 50$ & Perkenalan Narasumber & Narasumber \\
\hline $09: 50-11: 15$ & Materi & Tim panitia \\
\hline $11: 15-11: 50$ & $\begin{array}{l}\text { Praktik Pembuatan Google } \\
\text { Classroom \& Google Form }\end{array}$ \\
\hline
\end{tabular}

This work is licensed under a Creative Commons Attribution-NonCommercial-ShareAlike 4.0 International License. 
EmaiL: info@stmik.jayakarta.ac.id , tridharmadimas.jayakarta@gmail.com

E-ISSN: 2798-8295 (Online), P-ISSN: 2798-8554 (Print) Vol. 1 No.1, Juli 2021 DOI : https://doi.org/10.52362/tridharmadimas.v1i1.502 Halaman 30-36

3. Monitoring \& Evaluasi

Kegiatan bertujuan untuk melihat sejauh mana pemahaman para peserta pelatihan dalam hal ini guru, serta meminta feed back dari para guru terkait kegiatan pelatihan. Pada tahapan ini para peserta diminta untuk mengisi kuesioner google form yang telah diberikan oleh panitia.

Adapun gambaran metode pelatihan dapat terlihat dari bagan berikut ini.

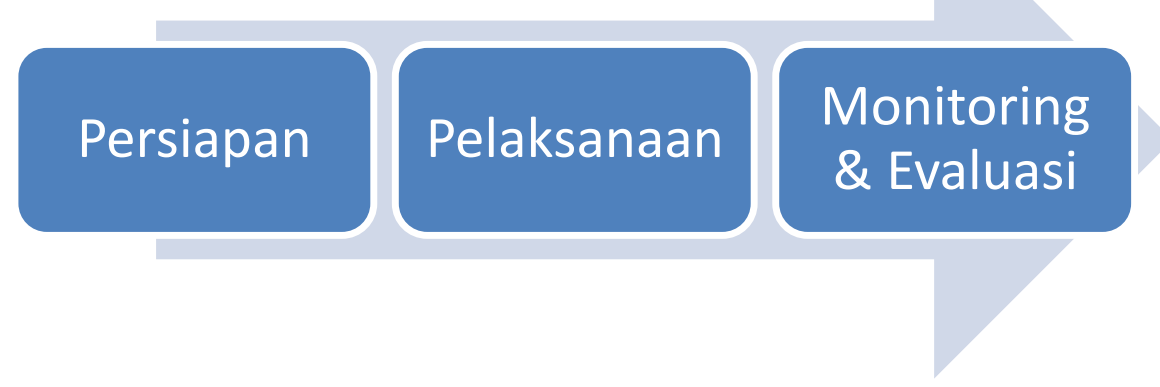

Gambar 1 Metode Pelatihan

\section{HASIL DAN PEMBAHASAN}

Kegiatan pengabdian masyarakat kali ini bertujuan untuk meningkatkan kemampuan TIK para guru guru SMA dan SMK di wilayah Jakarta, khususnya dengan sekolah yang telah bermitra dengan kampus STMIK Jayakarta. Secara umum kegiatan ini diikuti dengan baik oleh para peserta dalam hal ini adalah guru. Interaksi dan diskusi juga sering terjadi dalam sesi pemaparan materi. Sewaktu sesi praktik juga para guru sangat aktif dan bersemangat dalam mengerjakan kegiatan. Di akhir sesi diberikan kuesioner berbentuk google form [5] dengan harapan dapat memberikan umpan balik bagi para bapak dan ibu guru. Hasil kuesioner dapat terlihat pada hasil berikut ini.

a) Penyajian materi disampaikan dengan baik

\section{Penyajian materi disampaikan dengan baik}

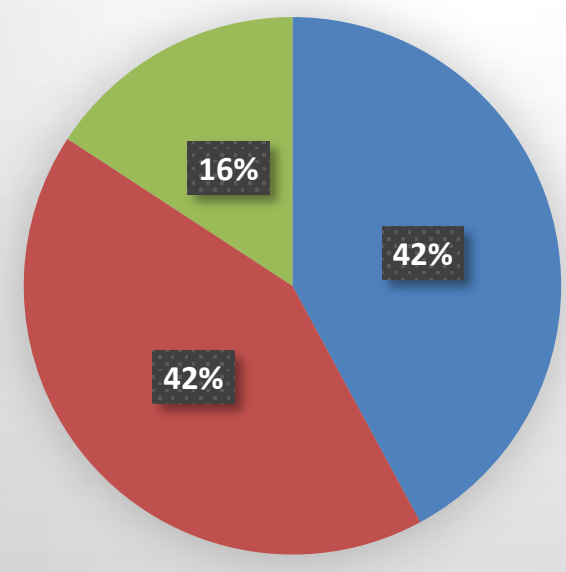

- Sangat Memuaskan

Memuaskan

Cukup Memuaskan

- Kurang Memuaskan

- Tidak Memuaskan 
EmaiL: info@stmik.jayakarta.ac.id , tridharmadimas.jayakarta@gmail.com

E-ISSN: 2798-8295 (Online), P-ISSN: 2798-8554 (Print) Vol. 1 No.1, Juli 2021

DOI : https://doi.org/10.52362/tridharmadimas.v1i1.502 Halaman 30-36

Gambar 2 Penyajian materi oleh narasumber

Sebanyak $42 \%$ peserta menyatakan sangat memuaskan terhadap penyampaian materi, $42 \%$ menyatakan memuaskan, dan sebanyak $16 \%$ menyatakan cukup memuaskan.

b) Apakah kegiatan ini bermanfaat bagi bapak/ibu?

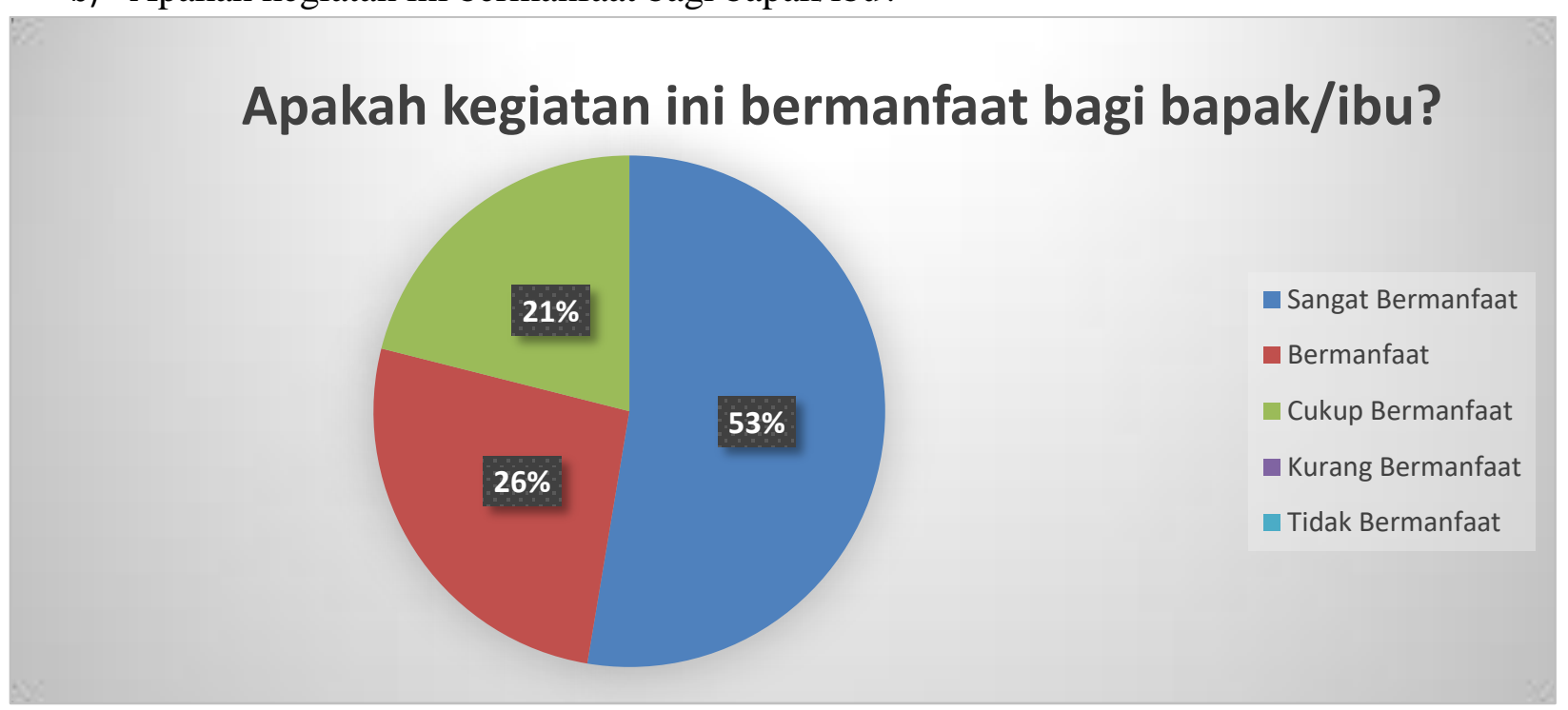

Gambar 3 Manfaat kegiatan Pelatihan

Dari gambar dapat terlihat sebanyak 53\% menyatakan sangat bermanfaat, 26\% menyatakan bermanfaat dan $21 \%$ menyatakan cukup bermanfaat terkait kegiatan pelatihan yang diselenggarakan.

This work is licensed under a Creative Commons Attribution-NonCommercial-ShareAlike 4.0 International License. 
TRIDHARMADIMAS: Jurnal Pengabdian Kepada Masyarakat Jayakarta

http://journal.stmikjayakarta.ac.id/index.php/tridharmadimas

EmaiL: info@stmik.jayakarta.ac.id , tridharmadimas.jayakarta@gmail.com

E-ISSN: 2798-8295 (Online), P-ISSN: 2798-8554 (Print) Vol. 1 No.1, Juli 2021 DOI : https://doi.org/10.52362/tridharmadimas.v1i1.502 Halaman 30-36

Dokumentasi Kegiatan

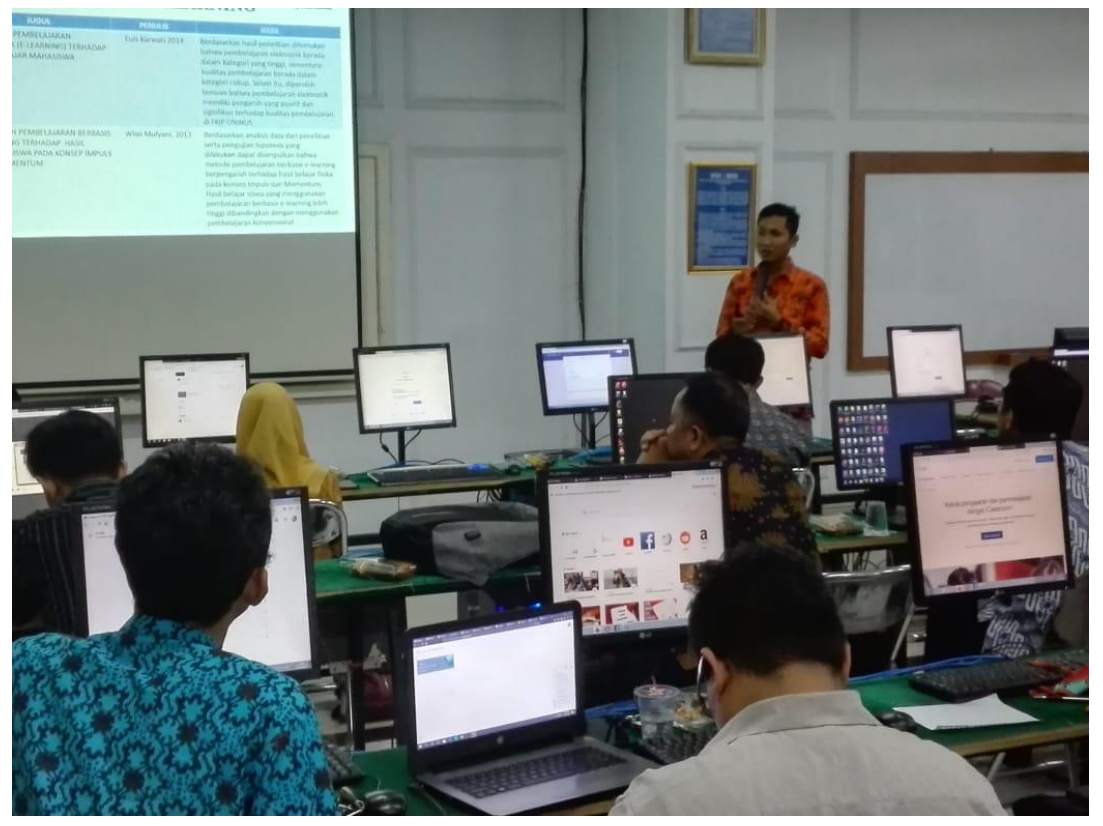

Gambar 4 Narasumber sedang memberikan materi

B Kelas
$\equiv \rightarrow \mathrm{C}$ Kelas Google Classroom trial
coba Kelas
$\begin{aligned} & \text { Anda menggunakan Classroom dari akun pribadi. Gunakan akun Workspace for Education untuk membuat Classroom lebih aman dan mendapatkan fitur } \\ & \text { tambahan. }\end{aligned}$

Kelas Google Classroom trial Coba Kelas

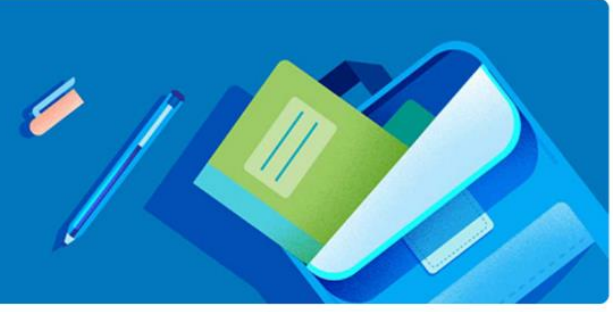

Mendatang

Hore, tidak ada tugas yang

Umumkan sesuatu ke kelas Anda

perlu segera diselesaikan!

Gambar 5 Contoh hasil pelatihan google classroom

\section{(c) (i)(2) (2)}

This work is licensed under a Creative Commons Attribution-NonCommercial-ShareAlike 4.0 International License. 


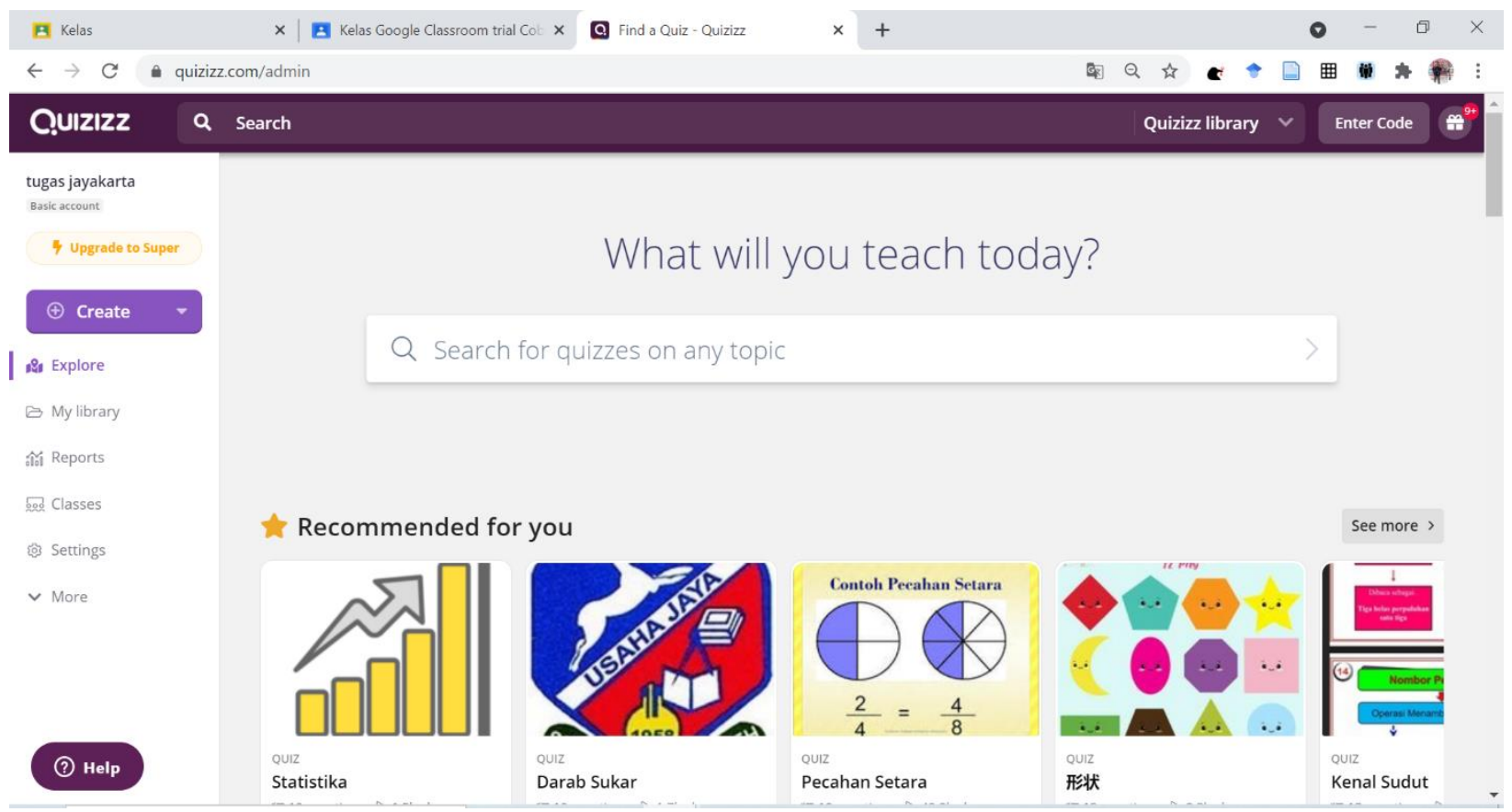

Gambar 6 Pembuatan Akun Quizziz

\section{KESIMPULAN}

Dari kegiatan yang telah dilaksanakan dapat disimpulkan :

1. sebagian guru masih belum dapat memanfaatkan teknologi informasi dengan baik.

2. Dengan pelatihan ini guru - guru menjadi lebih familiar dan bisa menggunakan teknologi informasi dalam melakukan proses belajar mengajar.

3. Kegiatan pengabdian masyakarat berjalan dengan baik dan sesuai dengan perencanaan.

4. Semua pihak termasuk guru merasakan dampak dan manfaat langsung dari kegiatan pelatihan ini.

\section{UCAPAN TERIMAKASIH (jika ada)}

Segala puji syukur kami panjatkan kehadirat Allah Swt, yang memberikan kesempatan dan juga Kesehatan sehingga pelaksanaan kegiatan pengabdian masyarakat dapat terlaksana dengan baik mulai dari persiapan, pelaksanaan sampai akhir acara. Ucapan terima kasih kami sampaikan kepada pimpinan kampus STMIK Jayakarta yang telah mensupport dana dan juga pemikiran serta fasilitas yang diberikan, sehingga kegiatan pelaksanaan pengabdian masyarakat ini dapat terlaksana dengan baik. Terima kasih kepada mitra sekolah yang membantu menyediakan waktu untuk diskusi dan juga bertukar pikiran terkait 
TRIDHARMADIMAS: Jurnal Pengabdian Kepada Masyarakat Jayakarta

http://journal.stmikjayakarta.ac.id/index.php/tridharmadimas

EmaiL: info@stmik.jayakarta.ac.id , tridharmadimas.jayakarta@gmail.com

E-ISSN: 2798-8295 (Online), P-ISSN: 2798-8554 (Print) Vol. 1 No.1, Juli 2021

DOI : https://doi.org/10.52362/tridharmadimas.v1i1.502 Halaman 30-36

permasalahan yang terjadi pada mitra. Tidak lupa pula kami ucapkan terima kasih kepada dewan dosen, dan juga seluruh pihak yang telah membantu pelaksanaan pengabdian masyarakat ini.

\section{DAFTAR PUSTAKA}

[1] D. Sartika, I. Saluza, and M. Amelia, "PELATIHAN PEMBUATAN E-LEARNING SEBAGAI MEDIA PEMBELAJARAN BAGI SISWA DI SMP NEGERI 29 PALEMBANG," vol. 1, no. 2, pp. 96-100, 2017.

[2] N. S. Hanum, "Keefetifan e-learning sebagai media pembelajaran (studi evaluasi model pembelajaran e-learning SMK Telkom Sandhy Putra Purwokerto)," J. Pendidik. Vokasi, vol. 3, no. 1, pp. 90-102, 2013.

[3] M. Yazdi, "E-learning sebagai Media Pembelajaran Interaktif Berbasis teknologi Informasi," J. Ilmua Foristek, vol. 2 (1), no. 1, pp. 143-152, 2012.

[4] A. Z. Sianipar, Saprudin, and Zulhalim, "PENGEMBANGAN MODUL STATISTIKA BERBASIS QR CODE UNTUK MELATIH HIGH ORDER THINGKING SKILLS (HOTS) MAHASISWA," vol. 5, no. 1, pp. 271-275, 2021.

[5] A. Z. Sianipar, "Penggunaan Google Form Sebagai Alat Penilaian Kepuasan Pelayanan Mahasiswa," no. 10, pp. 1-14, 2019.

This work is licensed under a Creative Commons Attribution-NonCommercial-ShareAlike 4.0 International License. 